\title{
Relationship of Stress among University Lecturers in Nigeria
}

\author{
Amina Abdullahi Ubangari, Dr. Raymond Bako \\ Ahmadu Bello University, Zaria \\ Department Of Physical And Health Education Education Thought And Concept (Educ 901)
}

\begin{abstract}
Stress can have impact on the performance of university lecturers in Nigeria. It takes a lot more than just working to earn a living and have a successful career in lecturing job. This paper among other things, examines the relationship of stress and academic performance among Nigerian university lecturers, source and types of stress. The paper explores Imeokparia's (2013) model on stress management (conceptual framework) to analyze the study and reviewed related empirical studies on relationship of stress and performance among university lecturers in Nigeria. Finally, the paper highlighted the effect of stress on the performance of Nigerian universities and proffers general and philosophical solutions to the challenges of stress among university lecturers
\end{abstract}

Key words: Relationship, stress, university, lecturers, Nigeria.

\section{Introduction}

Stress has become an integral part of lecturing job. The demand of lecturing job has increased the level of stress among lecturers in Nigerian universities. An optional level of stress can be a source of positive motivation to succeed (Edward, 2011). However, too much stress can cause physical and mental health problems (Niemi and Valniomaki, 1999). The nation-wide strike embarked by the Academic Staff Union of University (ASUU) in Nigeria which lasted for over five month is partly caused by stress related demands by the university lecturers termed "earned allowance" which includes over load allowance. Imeokparia, Ediagbonya (2013) opined that stress is the condition that results when person/environment transactions lead the individual to perceive a discrepancy, whether real or imagined between the demand of a situation and the resource of the person's biological and social system. Similarly, Gunnar, Herrera and Hostinar (2009) conceptualize stress as a condition in which an individual experiences challenges to physical or emotional wellbeing that overwhelm their coping capacity.

Stress is a part of the normal fabrics of human existence. Every individual regardless of race or cultural background, social and occupational status and even children experience stress in many ways (Oyerinde, 2004). It is an inevitable part of challenges that prompt mastery of new skills and behaviour pattern. However, when stress becomes excessive, difficulties occur and the sufferer experiences disrupted emotional, cognitive and physiological functioning. Stress may be acute or chronic in nature (Akinboye et al., 2002). Chronic stress is associated with the development of physical illness including such leading causes of death. The cost of stress in terms of human suffering, social and occupational impairment and mental illness is enormous (Crider, Goethal, Kavanaugh and Solomon, 2003).

Stress is a common experience. People may feel stress when they are very busy, have important deadlines to meet, or have too little time to finish all of their tasks. Often some people may be particularly vulnerable to stress in situations involving the threat of failure or personal humiliation. Khan (2005) observed that others have extreme fears of objects or things associated with physical threats such as snakes, illness, storms, or flying in an airplane and become stressed when they encounter or think about these perceived threats. Major life events, such as the death of a loved one, can cause severe stress. Stress occurs when there are demands on the person exceed his/her adjustive resources. There are physical stresses such as extreme cold, heat, the invasion of micro- organisms, physical injuries etc. Certain environmental social conditions on the other hand can also be damaging these are called Psycho-social stresses e.g. loss of job, death of a loved one. Stress depends not only on extreme condition but also on vulnerability of the individual and the adequacy of his/her system of defenses. Examples of Universal stresses include war, imprisonment, natural disaster such as fire burst, terror earth quack, disabling injuries and terminal illness. People react to the same stressor in diverse ways, in some who appear comparatively undisturbed and act an effective manner in spite of difficult situation. In contrast, others become disorganized, dazed, panicky and generally displaying the signs of severe emotional disturbances.

Stress can have both positive and negative effects. Stress is a normal, adaptive reaction to threat. It signals danger and prepares students to take defensive action. Fear of things that pose realistic threats motivates workers to deal with them or avoid them. Stress also motivates workers to achieve and fuels creativity. Although stress 
may hinder performance on difficult tasks, moderate stress seems to improve motivation and performance on less complex tasks. In personal relationships, stress often leads to less cooperation and more aggression. Janet (2003) opined that, if not managed appropriately, stress can lead to serious problems. Exposure to chronic stress can contribute to both physical illnesses, such as heart disease, and mental illnesses, such as anxiety disorders. Much of the stress in lives results from having to deal with daily hassles pertaining to studies, personal relationships, and everyday living circumstances. Many people experience the same hassles every day. Examples of daily hassles include living in a noisy work environment, commuting to school in heavy traffic, disliking one's fellow worker, worrying about owing money, waiting in a long cue, and misplacing or losing things. When taken individually, these hassles may feel like only minor irritants, but cumulatively, over time, they can cause significant stress. The amount of exposure people have to daily hassles is strongly related to their daily mood. Generally, the greater their exposure is to hassles, the worse is their mood. Studies have found that one's exposure to daily hassles is actually more predictive of illness than is exposure to major life events (Janet, 2003).

Selye (1989 cited in Crider, 2000) defines stress as the body's general response to environmental situation, which can lead to change in physical, emotional, behavioural or mental state. Stress according to Meeks-Mitchell and Heit (1982 cited in Oyerinde, 2004) is the non-specific response of the body to any demand made upon it. It is the biological response to events that threatens to overwhelm an individual's capacity to cope satisfactory in the environment. Dunkel-schetter and Lobel (2000) asserts that physiological stress is any particular relationship between a person and the environment that the person judges to be beyond his or her resources and jeopardizes his or her well-being. Kar (2002) viewed stress as an unpleasant state of emotional and physiological arousal that people experience in situations that they perceive as dangerous or threatening to their well-being. Additionally, "stress is a physical and mental response to everyday demands, particularly those associated with change" (Richlin-Klonsky \& Hoe, 2003). In recent years, "stress has become an important topic in academic circle" (Agolla \& Ongori, 2009) probably because of the fact that life in general is flooded by many stresses. Among civil servants, stress can be viewed as a positive or negative experience that affects their lives and performances. This is so because "office work is never without stressful activities" (Agolla \& Ongori, 2009). The experience of stress among civil servants is considered normal but "if stress is severe and/or prolonged, it can reduce performance; interfere with a staff's ability to participate in and contribute to work life; and increase the likelihood of substance abuse and other potentially damaging behaviors" (Richlin-Klonsky \& Hoe, 2003).

Concerning the causes of stress most studies have pointed to the fact that the incidence of stress is due to overwork (Laver, 2009). Graham (2008) stated that "poor management is the major cause of stress". Graham (2008) argued further that "stress is not the inability to cope with excessive workloads and the unreasonable demands of incompetent and bullying managers; stress is a consequence of the employer's failure to provide a safe system of work as required by regulation. Afolabi and Imhonde (2002) identified organizational causes of stress as organizational and extra-organizational stressor, group and individual stressors. While Akinboye (2002) identified the following as causes of stress in workplace: new management technique, office policies, long work hours, redundancies, bullying, and harassment, the National Women's Health Information Centre NWHI (2003) identified traumatic accident and death or emergency situation as causes of stress. It can also be a side effect of a serious illness or disease. The center also associated stress with daily life hassles, the workplace, and family responsibilities.

\section{Conceptual frame work}

This paper modified and adopted Imeokparia and Ediagbonga (2013) model on stress management. 


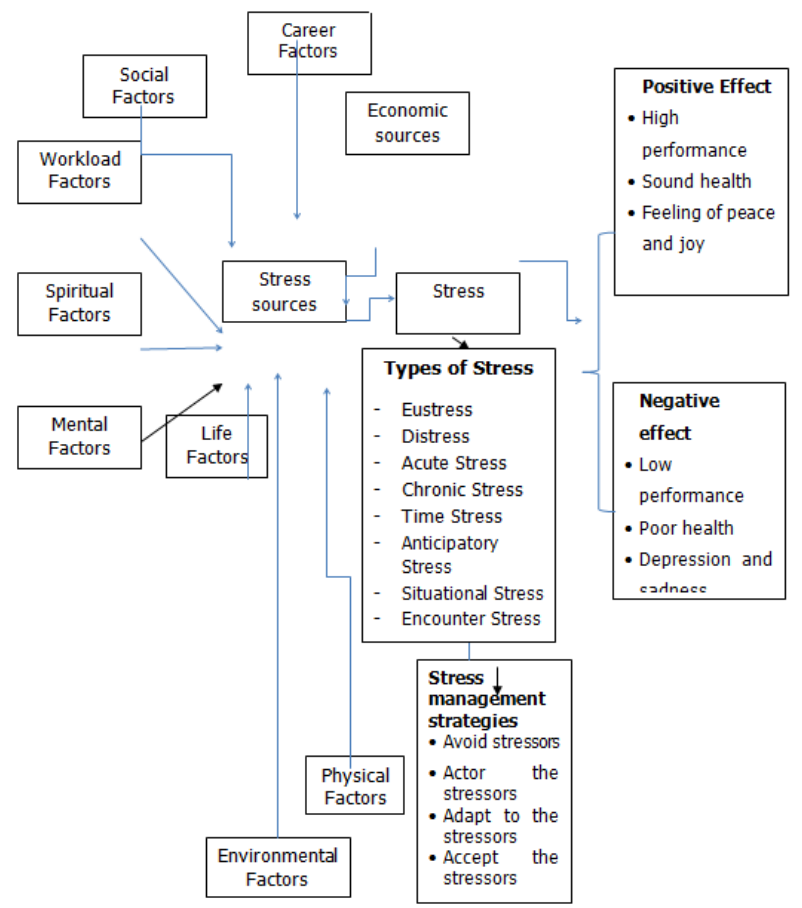

Fig.1 Imeokparia and Ediagbonya model on stress management.

Source: Author's field work.

\section{Conceptualizing Stress at Workplace}

Job stress among Nigerian university lecturers has become a critical issues and a matter of concern to Nigeria university teachers, "high level of stress among lecturers have been associated with decreased research productivity (black-burn and Bentley, 1993)" workplace factors have significant effect on human mental and physical health" (Yusoff, Khan and Azam 2013) as affirmed by Fisher (2011) "Teaching is a very stressful job because teachers are exposed to both physical and psychological stressors". Stressors have potentials to create physical and psychological symptoms among Nigeria university lecturers". Job stress has devastating effect for the educational institutions in terms of absenteeism, low performance, lower organizational commitment and turnover intentions (Tarus, Schreurs and Van lersel-Van Silfhout, 2001)." Job stress is both physical and emotional response of an employee to the unwanted workplace factors which are beyond the abilities of an employee (Cooper and Dewe, 2008). There are different types of stressors as identified by Beehr and Newman (1978), namely: Role expectation, job demands, and organizational internal, external environment. The identification of different stressors compelled researchers to start finding the interaction of stressors with other work factors such as work performance and motivation, job satisfaction etc. This led to the development of stress models. Job demand control model, (Karasek, 1979). Job Demand Resources model (Demeravti, Bakker and Schaufeli, 2001), and Person-environment fit model (Robert, 1987).Job performance is key to the achievement of organizational goals in any given context. Work performance of Nigerian university lecturers is central to the development of all sectors in the Nigerian economy. Hanif (2010) noted that factors like time management, maintaining a good communication channel with student, parent and institute administration often contribute positively to the faculty member's performance". As put by Cai and Lin, (2006)"faculty's performance can be classified into task and contextual performance. The task performance is the ability of faculty members to recognize the highlighted and explored organizational goals. It consists of teachers-students interaction, teaching value and effectiveness".

Philosophical Aspects of Stress: The philosophical aspect of stress is largely ignored; more attention is given to psychological and physical. Stress is partly hinged to our values and believes system and imagination. "Stress is the body-mind unconscious response to perceive threat or danger, it is rooted in the meaning our brain attributes to that event and our response to that perceived meaning (Graham, 2009)". Stress comes from our imagination- how we label things good or bad (everyday philosophy, nd). Lancaster (2006) noted that "stress relates to our values and belief system: people seem more concern with treating the system than the problem which maybe more philosophical". Everyone has personal values and beliefs. Some people value romantic relationship, other getting drunk every day while others value money or buying expensive cars and building mansions. These personal values are embedded in our cultural and religious belief and tend to contribute or modify our behaviors. Most people do not examine their belief system when it comes to managing stress 
(positive or negative stress)"negative effect of stress can occur when we behave counter to it" (Lancaster, 2006). Based on our value system, internally we behave differently. For example, a university lecturer who value time with his family may have little time to do so because he works for 15 hours in a day, while someone else may see this as an opportunity to provide more money for his children education and other family obligations. It may be a source of stress for an individual. What motivates one worker may overwhelm another.

\section{Sources of Stress among University Lecturers in Nigeria}

Stress in the work place can be sources of positive motivation in order to achieve success or it can hinder morale, relation and performance. Olatunji and Akinlabi (2012) Yusoff(2013) Wilkes et, al, (1998) identified the following source of stress among university lecturers "Lots of works load, inadequate ventilated office, noisy environment, multiple university problems, inadequate lecture halls, keeping pace with institutional demands, role expectation, emotional demand inter-personal relationship value and belief system. These stressors if not properly handled can be harmful or can cause early life. In general terms stress sources can be classified into three as affirmed by Edwards (2011):

i) An uncontrollable or unpredictable events: This might include accident, the loss of family member or love one and sudden loss of job

ii) Being over whelmed. Too many things and problems coming at once and too fast.

iii) Working beyond our capabilities, skill level or coping resource: Taking on a new job or task without proper training, parenting step children or caring for an elderly parents are common examples

\section{Types of Stress}

Imeokparia (20130 identified the following types of stress:

- Eustress: is a positive stress, it provides immediate strength to the individual. It is a result of haven achieved an outstanding feet in one's life. It maybe in form of passing an examination with good grades, child birth, winning an award. This stress often occurs for a short period of time and it create a sought of imbalance within the individual.

- Distress: it is a bad stress because it makes an individual vulnerable to illness

- Acute stress: it is a psychological condition arising in response to a terrifying or traumatic event. The ensuring physiological changes constitute a major part of the acute stress responses. Acute stress can be acute eustress mostly in small dose (pleasant, cheerful, thrilling, exciting stress) and acute distress mostly too much (cause of mental health problem and physical difficulties, tension, headache, upset stomach). The symptoms of acute stress usually appear within minutes of the impact of the stressful stimulus and disappear within 2-3days (often within hours)

- Chronic stress: in chronic stress the stressor is around for a longer time. This is the grinding stress that wears people away day after day, year after. Chronic stress destroys body, mind and life, it wreak havoc through long-term attrition. It is the stress of poverty, of dysfunctional families, of being trapped in an unhappy marriage or in a despised job or career. It is the stress with no hope, the individual gives up searching for solution.

- Time stress: it is a stress induced by time constrain. One worry about the number of things that one has to do, and fear that will fail to achieve something important. This is common in all facet of life. Lecturers are often faced with seminars, conference paper or VIVA date line. There is bound to be imbalance within the individual if he/she perceives that there may be no enough time to complete a given task.

- Anticipatory stress: this is the kind of stress that one can experience in an interview or concerning the future e.g. upcoming paper presentation by lecturers, job interview and events. Anticipatory stress is often occasioned by fear of failure.

- Situational stress: this stress is no anticipated by an individual and as such it is always sudden. This normally place the individual under pressure thereby experiencing series of hormonal discharge and fast heart beating. Conflict has been identified as the major cause of situational stress and effective conflict resolution skills have equally been identified as possible way out.

- Encounter stress: this type of stress occurs as a result of contact with other people. Some persons by virtue of their profession/ occupation are made to have contact with members of the public that may be stressed. Examples of these categories of workers/ professionals include medical doctors, police officers and psychologist.

\section{Relationship of Stress and Performance among University Lecturers in Nigeria}

There is no doubt that lecturing job in Nigerian universities is a herculean task. Considering the heavy work load associated with it. Russell Herman shares her experience as a faculty lecturer:

\section{"I typically come to work by 6am in preparation for 8am classes} every day and office hours every day and leave $5 \mathrm{pm}$. In the last two 
weeks I had 10 meetings with students on projects and a directed independent study. I did two peer classroom observations, Three events for teaching excellence, attended two colloquia, participated in panel discussion open to the public on the nation of time (which took hours of preparation for a ten minutes presentation), attended a two hour department meeting, attended a two hour meeting on evaluating faculty teaching, spent time reviewing annual reports for the previously mentioned meeting for an up-coming public seminar by a noted speaker, I also reviewed a couple of papers for professional journals, entertained student question when they come by outside of office hours, and wrote two reference letters for students. This past weekend my colleagues and I ran five events for the regional science Olympiad, which require getting majors to volunteer and to draft the event and spend 6am to almost 5:00pm, on campus on Saturday. Well, that is almost all I have done the past two weeks. I also worked on putting the current jet (journal) together, I am sure I am leaving something out. Like editing and posting video lectures of one my classes, grading homework and hoping to find time to finish the draft to a text book for my publisher"'(Herman,2013).

This scenario is typical of what most Nigerian university lecturers experience Question about university lecturer workload is not new. The combination of infrastructural and inadequate manpower has over the years led to low performance and productivity in Nigeria universities. The Nigeria lecturers are over stretched forcing them to work under pressure and stressed conditions. Apart from the challenges of manpower and infrastructure such as lecture theatres, laboratories and residential quarters for teaching and support staff, lecturer to student ration has worsened. "Needs report on public university said the Nigerian universities are grossly understaffed relying heavily on part time and under qualified academics" (Punch, Nov, 13, 2012).

\section{Review of Related Empirical Studies on Relationship of Stress and Performance among University Lecturers in Nigeria}

Yusoff (2013) carried out a study on job stress, performance and emotional intelligence in academia. The study sampled out 65 faculty members from two universities in Pakistan including one public and other private sector university. Data was collected using questionnaire, and was analyzed through descriptive and inferential statistical techniques. It was found that a negative relationship exist between job stress and performance, whereas a strong positive was found between emotional intelligence and job performance. The finding revealed that the faculty members in the higher education institution of Pakistan should focus not only on identifying the job stress factors but should also try to manage their emotional competence by working in a conducive atmosphere. In this way they can deal with problems of job stress and boost up their performance. The outcome of this study implies that negative relationship exists between job stress and lecturer's performance in Nigeria and that university lecturers in Nigeria should identify the job stress factors and try to manage their emotional competencies by working in a conducive atmosphere, this would deal with problem of stress and boost their performance. In a study of job satisfaction among university staff in Malaysia, by

Ahsan, Abdullah, YongGunfle and Alam (2009), the study identified the following determinants of job stress; management role, relationship with others, work load pressure, homework interface, role ambiguity and performance pressure. The sample of the study consists of public academicians from Klang Valley area in Malaysia. The finding of the study showed that, there is a significant relationship between the construct tested, the result also showed that there is significant negative relationship between job stress and job satisfaction. The implication of this study is that, there is significant relationship between management role, relationship with others, workload pressure, homework interface, role ambiguity and performance pressure on Nigerian lecturers. The study also suggested that there is significant negative relationship between job stress and job satisfaction among university lecturers in Nigeria. Tahir (2011) investigated the effectiveness of teaching stress on academic performance of college teachers in Pakistan, the study sample out 106 college teachers of public and private sector selected through stratified sampling technique. The test of regression analysis t-test, one way ANOVA and two ways ANOV were applied. The study revealed that intrinsic and extrinsic variables have positive effect on academic performance of college teachers. The study also showed that significant difference was found between academic performance of teachers of public and private colleges. In relation to the study carried out by Tahir (2011), it indicates that intrinsic and extrinsic variable have positive effect on the academic performances of Nigerian university lecturers. 
The above empirical studies on stress and performance clearly showed that there is significant relationship between stress and performance among university lecturers in Nigeria.

\section{Effect of Stress on the Performance of University Lecturers in Nigeria}

Stress is a subjective phenomenon that differs for each of us. Things that are good and pleasurable for some people might be distressful for others. People respond to stress differently. Below are some of the challenges of stress on the performance of Nigerian university lecturers.

- Reduced work productivity, depression

- Lecturers lie or give excuses to cover up poor work

- Frequent headaches, neck ache, back pain and muscles spasms.

- Social withdrawal or isolation

- Constant tiredness, weakness, fatigue

- Low sexual performance

- Increased frustration, anger and hostility.

- Number of minor accident increase

- Difficulty in taking decision

- Increase smoking, alcohol or drug use

- Trouble learning new information

- Insomnia, nightmares, disturbing dreams (Klinic community health centre, 2010).

\section{Conclusion/Recommendation}

From the foregoing, it is evidence that there is relationship between stress and performance among Nigerian university lecturers, the university lecturers are working in an un-conducive environment, poor condition of service and motivation. All these stressors culminate to slow down productivity among university teachers in Nigeria.

\section{Recommendations}

The outcome of this paper indicates that, there is the need to drastically reduce the work load of university lecturers in Nigeria. The lecturer-student ratio should be at least 1:35. This can be achieved by employment more quality and qualified manpower into the Nigerian universities. Recreational centers should be provided by the government and stake holders in Nigerian education across all Nigerian universities. The philosophical aspect of stress should be addressed by Nigerian lecturers. Our brain and body are completely pliable; we can shape our brain through thoughts and action. Lancaster (2006) recommended philosophical aspect of management stress.

- Examine your value system. study your behavior and ask you self the following questions:

- Why did I do that? What should I do in a similar situation? What do I value more or less? In effect you are asking yourself "who am I"

- Dream: find a quiet place and time then identify your ideal life styles. This begs another important question. How should I live, how much of my dreams, life style would really contribute to my happiness. As judged by man own criteria. Am I ignoring other important values?

- Problem solving - identify the problem brain storm ideas, evaluate the pros and cons of each idea then select the best solution, next act and evaluate. This step should continue throughout one's life.

\section{References.}

[1]. Ahsan, N. \& Abdullahi, Z. \& Yong Gunfle, D \& Alam, S.S (2009). A Study of Job Stress on Jobs Satisfaction Among University staff in Malaysia: Empirical Study. European Journal of Social Science Vol. 8. No. 1 pp 21-130

[2]. Beehr \& Newman, (1978) Job Stress, Employee Health, and Organizational effectives: Facet Analysis, Model and Literature Review, Personal Psychology, 31, (4) 665-669.

[3]. Blackburn, R.T., \& Bentley, R.J (1993): Faculty Research Productivity: Some Moderators of Associated Stressors. Research in High Education. 34, 725-745.

[4]. Brush (1993). Everyday Philosophy (n.d) Dealing With Stress and Challenges/Body mine Awakening. Retrieve December, 2013 from http://www.bodymineawakening.com/everyday-philosphy

[5]. Cai and Lin (2006). Theory and Practice on Teacher Performance evaluation, Frontier of Education in China 1(1), 29-39.

[6]. Commensurate Dimension, Time Perspective and Mechanism. J. Voc, Behaviour, Dec 26, 2013 From http://www.punch.com/Education/Nigeria-universities-lack-enough-lecturersreport

[7]. Demerout I. and Bakker, and Schaufeli (2001). The Job Demand Resources Model of Burn out, J. APP. Psychology, 86(3), 499-512

[8]. Edward, D. (2011). Overcoming Stress: Challenge for the Workplace. Innovative Solution. Better Health. Retrieved November 02. 2013.

[9]. Effectiveness: Facet Analysis, Model and Literature Review, Personnel Emotional Intelligence on Academia. Basic Appl. Sci. Res, $3(6) 1-8$

[10]. Fisher, (2011). Factors Influencing Stress; Burnout and Retention of Secondary Teachers. Current issue in Education, 14 (1), 1-37. 
[11]. Graham, L. (2009). Skillful Ways to Deal With Stress and Trauma. Retrieve, Dec. 22. 2013 from http://LindagrahamNFt.net/resource/published-articles/skillful-ways-to-deal-with-stress-and-trauma

[12]. Gunnar, M. R. \& Herrera, A. \& Hostina, C. (2009). Stress and Early brain Development. Retrieved, Nov, 8, 2013, from http://www.childencyclopedia.com/document/Gunnar-Herrera-HostinarANGXP.Pdf

[13]. Hanif, R. (2010). Teacher Stress-Job Performance, and Self-Efficiency Among Women Teacher: Lap Lambat Academic Publisher.

[14]. Herman, R. (2013). How Much do Faculty Work? Journal of Effective Teaching. Vol. 13. No 1.

[15]. Imeokparia, P.O. \& Ediagbonya, K. (2013) Stress Management: An Approach to Ensuring High Academic Performance of Business Education Students European Journal of Education 5(1), 2013

[16]. Karasek, (1979). Job Demand, Job Decision Latitude and Mental Strain: Implications for Job Redesign Administration Science Quarterly, 24 (2) 265-308 International Journal of Palliative Nursing 4(1)

[17]. Klinic Community Health Care Centre (2010) Stress and Stress Management. Retrieved Nov. 12 2013. From http://www.childencyclopedia.com/document

[18]. Lancaster, M. (2006). Stress a Philosophical Approach/Fitness. Japan. Retrieved Nov. 10, 2013. http://www.fitnessjp.com

[19]. Moderators of Associated Stressors. Research in Higher Education, 34, 725-745

[20]. Niem, P. M. \& Vainiomaki, P.T. (1999). Medical Students Academic Distress, Coping and Achievement Strategies During the PreClinical Years. Teaching and Learning Medicine, Vol, 11, 125-134 Nov, 10, 2013.

[21]. Olatunji, B.F \& Akinlabi, F.B (2012). Gender Influence of the Stress Experience of University Lecturers. European Journal of Business and Social Science Vol. 1 No. 4 pp 56-62.

[22]. Punch (Nov 13, 2012). Nigerian Universities Lack Enough Lecturers. Retrieved Dec. 26, 2013 from http://www.punch.com/education/nigerian-university-lack-enough-lecturers-reports/

[23]. Relationship of Stress a Performance Over University Lecturers in Nigeria. Retrieved November 12, 2013.

[24]. Robert, D (1987). Personal-Environment Fit Theory and Organization: Commensurate Dimension Time Perceptive and Mechanism. J.Voc, Behaviour, 31 (3), 248-267.

[25]. Tahir, A.Q. (2011) Effectiveness of Teaching Stress on Academic Performance of College Teachers in Pakistan. International Journal of Humanities and Social Science Vol. 1 No. 3 pp 123-129

[26]. Taris, S. and Van Lersel-Vansilfhout (2001). Job Stress, Job Strain, and Psychological Withdrawal Among Dutch University Staff: Toward Dual Process Model for the effect of Occupational Stress, Work and Stress, 15 (4), 283-296.

[27]. Teachers Current Issues in Education 14(1), 1-37. Vol. 13. No 1.

[28]. Wilkes, L. and Beale, B and Hall, E. and Rees, E. and Watts, B. Denne. C. (1998). Community Nurses Description of Stress When Caring in the Home. International Journal of Palliative Nursing, 4 (1)

[29]. Yusoff, R.B, \& Khan, A. \& Azam, K. (2013) Job Stress, Performance and Emotional Intelligent in Academia. J. Basic. APPL. Sci. Res 3 (6) 1-8. 